Volume 9. No. 4, April 2021

International Journal of Emerging Trends in Engineering Research

Available Online at http://www.warse.org/IJETER/static/pdf/file/ijeter32942021.pdf

https://doi.org/10.30534/ijeter/2021/32942021

\title{
STATCOM with Fuzzy-PI Controller for Low Voltage-Ride through Enhancement of DFIG based Wind Farm
}

\author{
${ }^{1}$ Stalin Kumar Samal ${ }^{*}{ }^{2}$ Ritula Thakur, ${ }^{3}$ Shivaji Karad \\ ${ }^{1}$ M.E (Instrumentation and Control) NITTTR, Chandigarh, India, samal.stalinkumar@ gmail.com \\ ${ }^{2}$ Faculty of Electrical Department NITTTR, Chandigarh, India, ritula.thakur@gmail.com \\ ${ }^{3}$ PhD Scholar of Electrical Department NITTTR, Chandigarh, India, shivaji.karad@gmail.com
}

\begin{abstract}
This paper represents the study of Fuzzy Logic Control-Based STATCOM devices to enhance the capabilities of the low voltage-ride through of a grid connected DFIG based wind farm and its comparison with conventional STATCOM device. The proposed FLC based STATCOM device have designed using MATLAB/Simulink. Compare to the output responses of the voltage, currents, speed, real power and reactive power of both stator as well as rotor of the two investigated systems during grid faults, the STATCOM with fuzzy-PI controller gives best performance with faster recovery, adjustable speed, smoother current profiles and better reliable than traditional controller.
\end{abstract}

Key words: Doubly-Fed Induction Generators, Fuzzy logic controller, Wind Turbine, Low Voltage Ride-Through, Grid necessities, Static Synchronous Compensator (STATCOM).

\section{INTRODUCTION}

Presently the wind power generation systems are one of the most supportable energy resources, which have been growing quickly all over the world. The quickly growth has been stimulated the operation of grid code requirements for the interconnection of wind farms. During grid faults, the mechanism of DFIG captivates more active, because of the technologies employed in the wind farm. International grid codes set down that the generator should be enhance the Fault ride-through (FRT) capability as well as network stability during fault at the grid [1].The major disadvantages of DFIG based on wind farm is more intuitive to grid disturbance,i,e the voltage drop at grid. However the dropped in Voltage will unbalance the three-phase alternating current of the grid with the output real and reactive power as well as the dc- link voltages of the generator connected to the grid. So to overcome these appropriate protection scheme with fault ride through techniques are needed [2].The Static Synchronous Compensator (STATCOM) is a power electronic based Shunt flexible ac transmission. System (FACTS) commonly utilized to supply the additional reactive power to compensate the DFIG during fault condition [3]. When the voltage of the grid has asymmetrical defects,i,e the change in current will suddenly high. At that time the whole grid will have big reactive power fluctuations. Nevertheless, the STATCOM is insufficient to prevent the system from either rotor over-current or dc-link overvoltage. However to improve the full system protection, there will be a combined based advanced techniques,i,e the fuzzy-PI controller could be able to conduct Fuzzy feedback processing and modification of PI parameters Via the creation of fuzzy rules online, which would enhanced the system complexity as well as robustness during the fault [4].However, based on the researcher experience the fuzzy logic control has a powerful independence in the development of fuzzy rules [5]. In this paper, a conventional STATCOM and a Fuzzy-PI based STATCOM is proposed. The simulation results are given to compare the both input and output performance of both the conventional STATCOM and FLC based STATCOM with that of the classical PI controller.

\section{DESIGN OF STATCOM WITH SELF TUNED FUZZY PI CONTROLLER}

\subsection{Design of Fuzzy-PI controller:}

The Controlled Error (E) and rate of Change in Error(CE) of the Fuzzy-PI controller would be consider as an Input variable based on the conventional PI controller and to modify the PI parameters via out- put variable based on the Fuzzy rule, which established in the fuzzy-PI Controller. The theory of Fuzzy logic controller shown in Fig.1. [6]- [8].

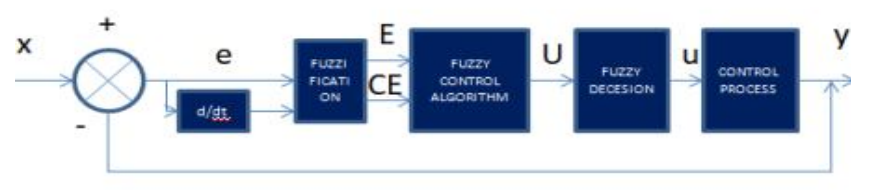

Figure 1: Schematic representation of fuzzy logic control 
After dealing with the extracted variables, they are fuzzified. Based on the fuzzy rules, the calculations process of fuzzifications will be continued through ratio and differential. When the fuzzifications will completed, the variables of the output will be obtained. However in the next step, these variables are differentiated with these PI parameters to modify consequently. The fuzzy rules followed by PI controller are shown in Table 1 below. The Fuzzy-PI STATCOM model is shown in Figure.2.

Table 1: FLC rules table

\begin{tabular}{|l|l|l|l|l|l|l|l|}
\hline E / CE & NB & NM & NS & ZE & PS & PM & PB \\
\hline NB & NB & NB & NB & NB & NM & NS & ZE \\
\hline NM & NB & NM & NM & NM & NS & ZE & PS \\
\hline NS & NB & NM & NS & NS & ZE & PS & PM \\
\hline ZE & NB & NM & NS & ZE & PS & PM & PB \\
\hline PS & NM & NS & ZE & PS & PM & PB & PB \\
\hline PM & NS & ZE & PS & PM & PM & PB & PB \\
\hline PB & ZE & PS & PM & PB & PB & PB & PB \\
\hline
\end{tabular}

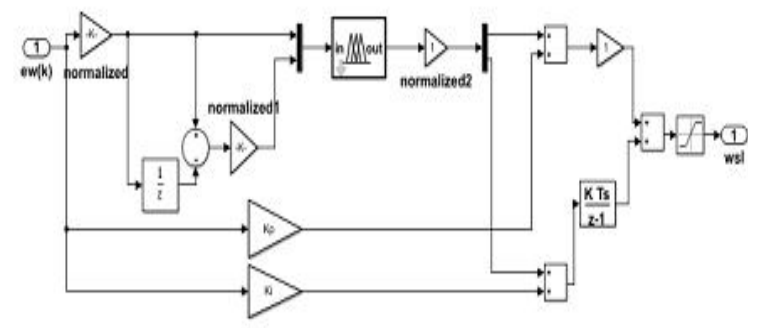

Figure 2: Simulation of fuzzy-PI Controller

The major objective of this research is to implement the Fuzzy-PI controller to the STATCOM's controller. In the variable parameter simulation model configurations, the scale between the regulated Error(E)and rate of Change Error $(\mathrm{CE})$ is $[-1,1]$, where the range of rate of change of deviation $(\Delta \mathrm{e})$ is $[-1,1]$. The variation range of the $\mathrm{Kp}$ performance parameter is $[-1,1]$, and the Ki range is $[-1,1]$, whose curves of operation followed by trigonometric curves regulation of features shown in Figure 3. Next with the collected voltage, the fuzzy processing is carried out, by contrasting the performance with that of the integral and ratio parameters and then modify the parameter of the PI.

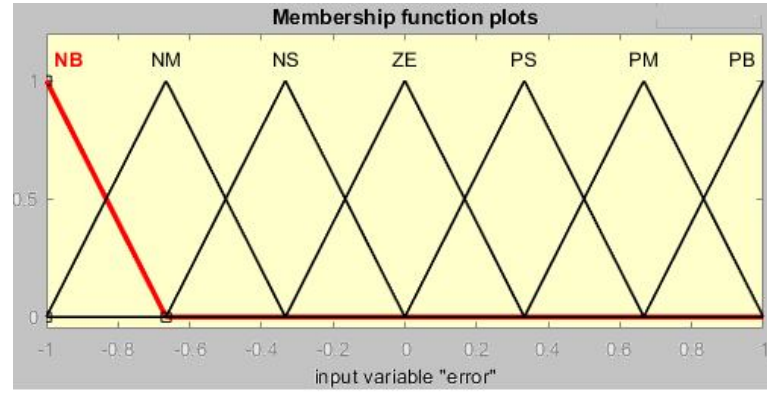

(a) Error "E"

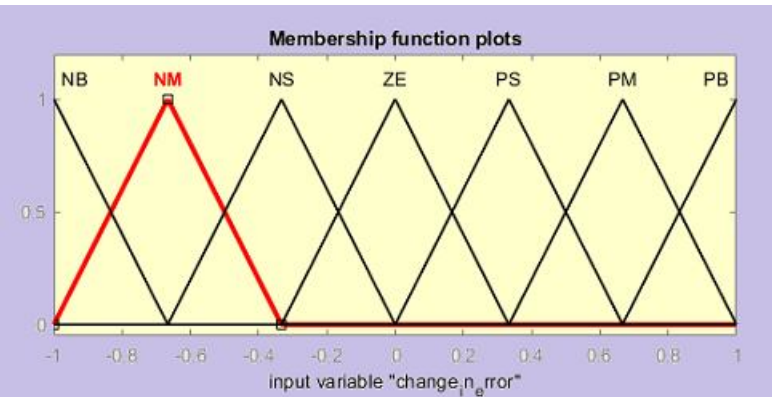

(b) Change in Error "CE"

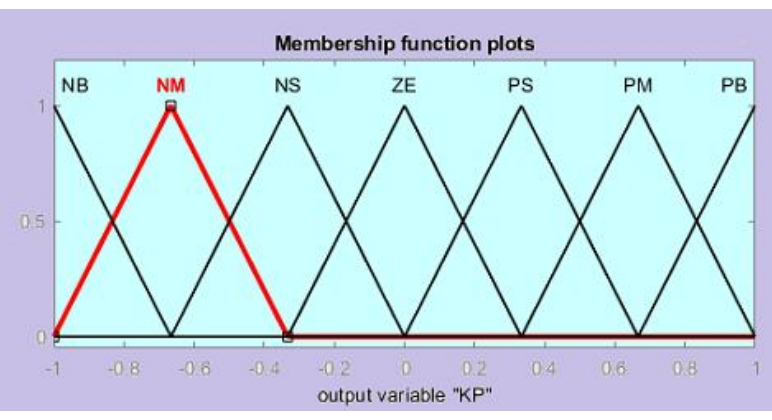

(c) Output of "Kp"

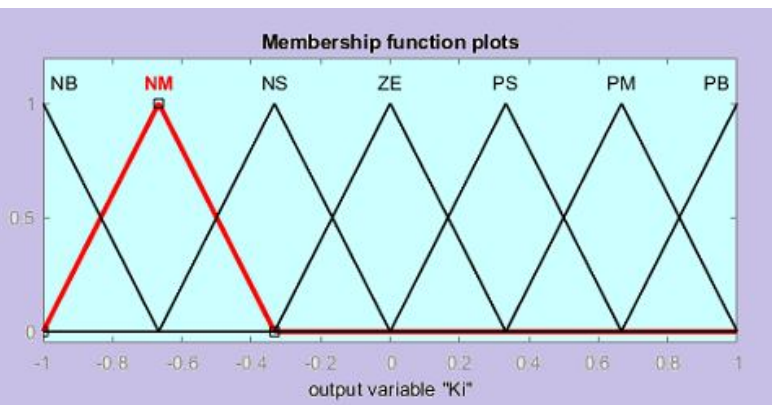

(c) Output of "Ki"

Figure 3: Represents the FLC membership functions: (a)Error "E",(b)Change in Error "CE",(c)Output of "Kp" and (d)Output of "Ki". 


\subsection{Established STATCOM Simulation Model:}

Dynamic compensation can be achieved through the STATCOM by changing the voltage on the AC side of the power grid and reactive currents that are absorbed or released according to the altering voltage. The basic STATCOM structure is displayed in Fig.4.Dynamic compensation can be achieved by STATCOM by changing the three phase voltage at the grid side as well as the reactive power that are absorbed or released according to the altering voltage. It binds the circuit while running to the on-off grid of fully regulated electronics modules and modifies the reactive changes i.e. the direct voltage into the alternating voltage through voltage source converter (VSC).The reactive power would be drawn up by the STATCOM, when the voltage at the grid side is higher than the voltage of the STATCOM i.e. the STATCOM would be in rectifiers state. In the other hand, the reactive power will be delivered by the STATCOM, when the grid side voltage is lesser than the voltage of the STATCOM i.e., the STATCOM will be in the state of inverter. The STATCOM link to the WECS that employs with DFIG, which incorporate with a two-level voltage source converters, a dc source, filters and coupling transformer, which connected parallel to the voltage source converter with the grid. The STATCOM and the grid are usually mounted with the coupling transformer that isolate the voltage i.e., lower voltage of the STATCOM from the higher voltage of the grid system. The filter, which located at the Point of Common Coupling (PCC) i.e, for reducing the harmonics of the system as well as enabling greater efficiency of power. The voltage source converter transforms the dc source voltage, i.e. from the storage unit through a storage device towards the output voltages for 3 -phase ac supply. Appropriate alteration of the magnitude as well as phase voltages of the STATCOM outputs allows efficient regulation of active as well as reactive power interchanges connecting to the STATCOM with the three phase ac supply of the grid. During normal operation ,the control mechanism including the phase locked loop process(PLL) will tracking the phase angle as well as magnitude of the supply voltage between the STATCOM and grid. As also detects the incident of sag in voltage, when there is fault. A battery is connected the DC input of the voltage source converter. The voltage source converter switching process is based on sinusoidal pulse width modulation procedure that provides ease and simplicity outputs. The switching frequency are set to be in the range 1800 to $2000 \mathrm{~Hz}$. The error signal will be the feedback of the controller, which can received as well as measured the voltage from the reference voltage and the rms voltage of the terminal. The rectification of this error will be processed by a PI controller. The output of the results,i,e rectify as zero error are supplied to the signal of the pulse width modulation of the generator. As a result the load voltage,i,e in rms value will be taken up to the reference voltage. The differential equations, which the STATCOM connected at the Point of Common Coupling, can be defined as:

$$
\begin{aligned}
& L \frac{d i_{\pi}}{d t}=\left(v_{c}-v_{u 1}\right)-R_{i u} \\
& L \frac{d i_{b}}{d t}-\left(v_{b}-v_{b 1}\right)-R_{i b} \\
& L \frac{d i_{b}}{d t}=\left(v_{a}-v_{b 1}\right)-R_{i c}
\end{aligned}
$$

From above equations(1),(2)and(3), here $i_{a}, i_{b}$ and $i_{c}$ are the line currents of the STATCOM.

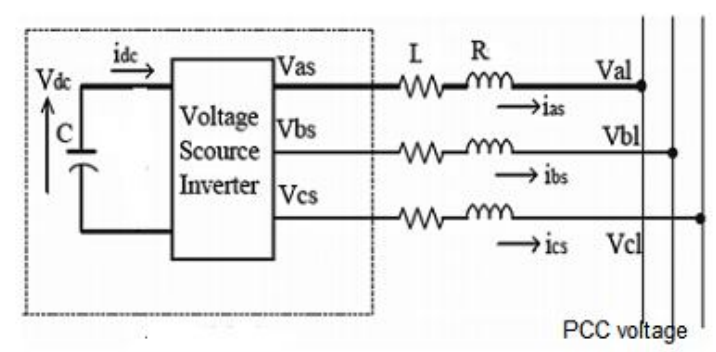

Figure 4: STATCOM Configuration model

Where $\mathrm{v}_{\mathrm{a}}, \mathrm{v}_{\mathrm{b}}$ and $\mathrm{v}_{\mathrm{c}}$ are the voltages at the Point of CommonCoupling. $\mathrm{v}_{\mathrm{a} 1}, \mathrm{v}_{\mathrm{b} 1}$ and $\mathrm{v}_{\mathrm{c} 1}$ are the terminal voltages of the inverter. $\mathrm{L}$ and $\mathrm{R}$ indicates the equivalent losses of both conduction and inductance for the transformer as well as the filter.

In $\mathrm{d}-\mathrm{q}$ frame the synchronously rotating three phase currents and voltages are:

$$
\begin{aligned}
& L \frac{d i_{i t}}{d t}=\left(v_{d l}-v_{d l}\right)-R_{i l l}+w L_{i b} \\
& L \frac{d i_{a d}}{d t}=\left(v_{q}-v_{q 1}\right)-R_{i q}+\omega L_{i d}
\end{aligned}
$$

Where the angular velocity of the synchronize voltage represents as $\omega$. By minimized the harmonics of the voltage produced by the inverter terminals, based on the Pulse width modulation technique, the output voltage at that terminals can be written as:

$$
\begin{aligned}
& v_{d 1}=K m v_{d c} \sin \alpha \\
& v_{a 1}-K m v_{a c} \cos \alpha
\end{aligned}
$$

The instantaneous real as well as reactive powers, which are at the Point of Common Coupling, are:

$$
P-1.5 v_{a} i_{\mathrm{d}}+v_{\mathrm{q}} i_{\mathrm{q}}
$$


Stalin Kumar Samal et al., International Journal of Emerging Trends in Engineering Research, 9(4), April 2021, 518 - 523

$$
P=1.5 v_{L}{ }^{i} u_{u}+v_{u} i_{u}
$$

The instantaneous value at the DC side i.e. instantaneous power will be:

$$
P=v_{z c} c \frac{d v_{d v}}{d t}
$$

From equations(8),(9) and (10)the equation of DC capacitor based on STATCOM current is:

$$
\frac{d v_{i c}}{d t}=1.5 c\left(v_{c} i_{d}+v_{q} i_{q}\right)
$$

Assume the d-axis, which equated with the vector sum of instantaneous voltage $v_{q}$ with dropping resistance $\mathrm{R}$, for the STATCOM is:

$L \frac{e_{l d}}{d t}=\left(v_{d}-K m v_{d c} \sin \alpha\right)+\omega L_{t q}$

$L \frac{d_{d q}}{d t}=\left(K m v_{d c} \cos \alpha-\omega L_{i d}\right)$

$\frac{d v_{d z}}{d t}=1.5 v_{d} i_{d}$

Where, the reactive power can be expressed as:

$$
Q-1.5 v_{d} i_{q}
$$

However the DC-voltage $v_{\tilde{u} c}$ can therefore be governed by $i_{d}$ and $i_{q}$ of the d-q axis, which are necessary to balance the reactive power as also the point of common coupling voltage. The overall circuit simulation model of DFIG based wind generation systems are shown in fig.5(a);fig.5(b) is the configuration of the control circuit. The STATCOM's control circuit layout embraces the forward current control strategy with dual closed loop systems. As for the outer regulating loop of the voltage, i,e create a distinction in between these components $\left(v_{d}, v_{q}\right)$ and that setup point through PI controller converted these components into $i_{c}$ and $i_{u}$, which regulate the internal current loop.

\section{ANALYSIS WITH DISCUSSION OF SIMULATION RESULTS}

The parameters of the STATCOM with Fuzzy PI control based on wind generation system equipped with DFIG model are:1.5 MW range of the wind generation system is installed, the specifications of the PI controller for the outer loop of the STATCOM voltage control is [ $\left.\begin{array}{ll}1 & 0.02\end{array}\right]$ and for the inner current control the parameters of PID is [180 3200 $1]$.

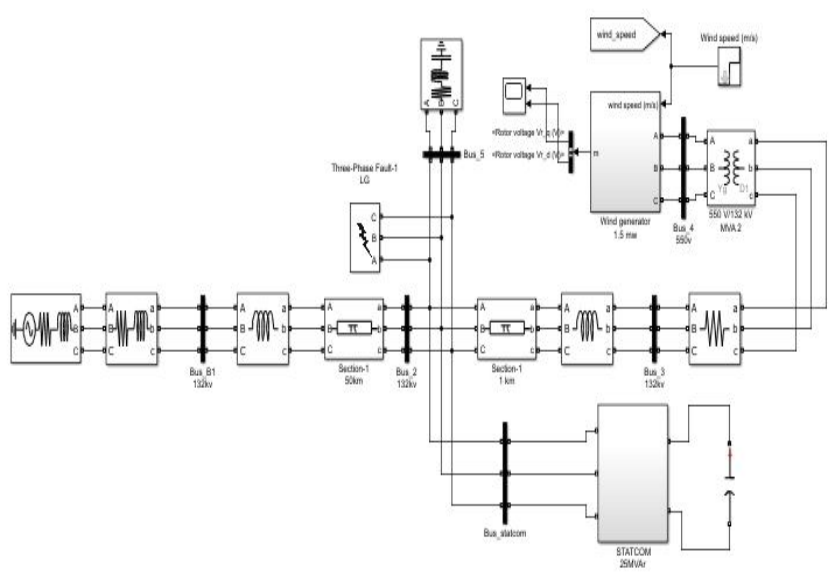

(a) Overall Simulation Model

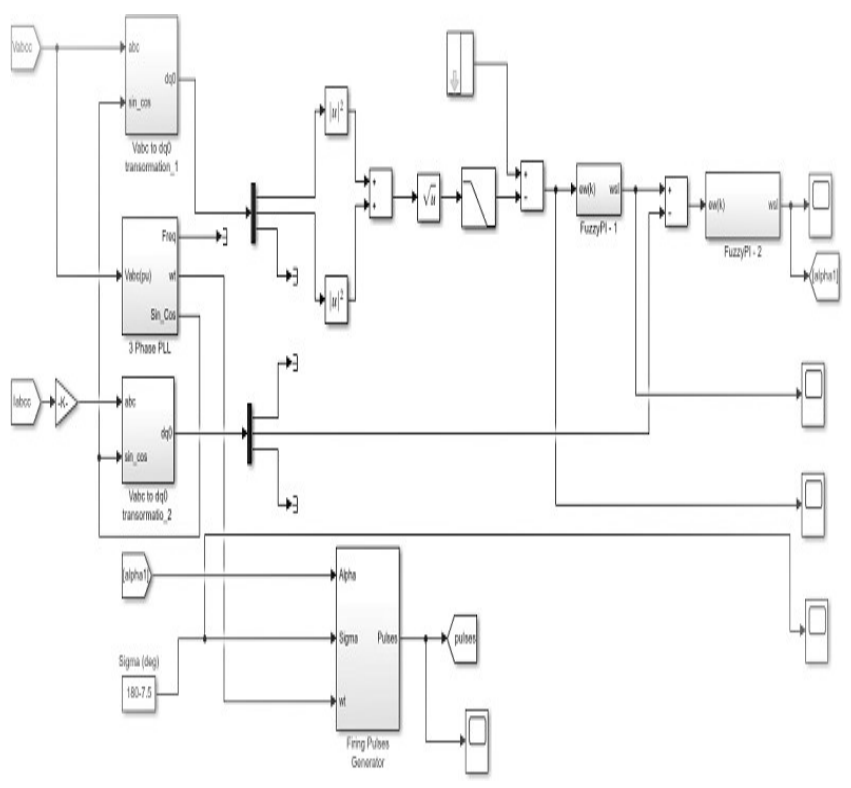

(b) Control structure

Figure 5: Represents :(a)Overall Simulation Model,(b)Control Structure

To examine the overall system performance, assuming the ground fault of A phase, which investigate the line-to-ground faults nearing by bus- 2 occurring at the grid. The time period of fault was 0.15 second, which happens at 0.30 second and removed after 0.45second.The differentiation of output results, which is varying by the use of STATCOM with PI control as well as STATCOM with Fuzzy-PI control are seen in Fig.6. From fig.6 it is clears 
that, the variations, which produced by the STATCOM with Fuzzy-PI controller is minimized, comparing with PI controller. The entire reactive powers fluctuations, which caused by its fault time clearing are relatively less as compare to conventional controller with stable in transient period of the system.
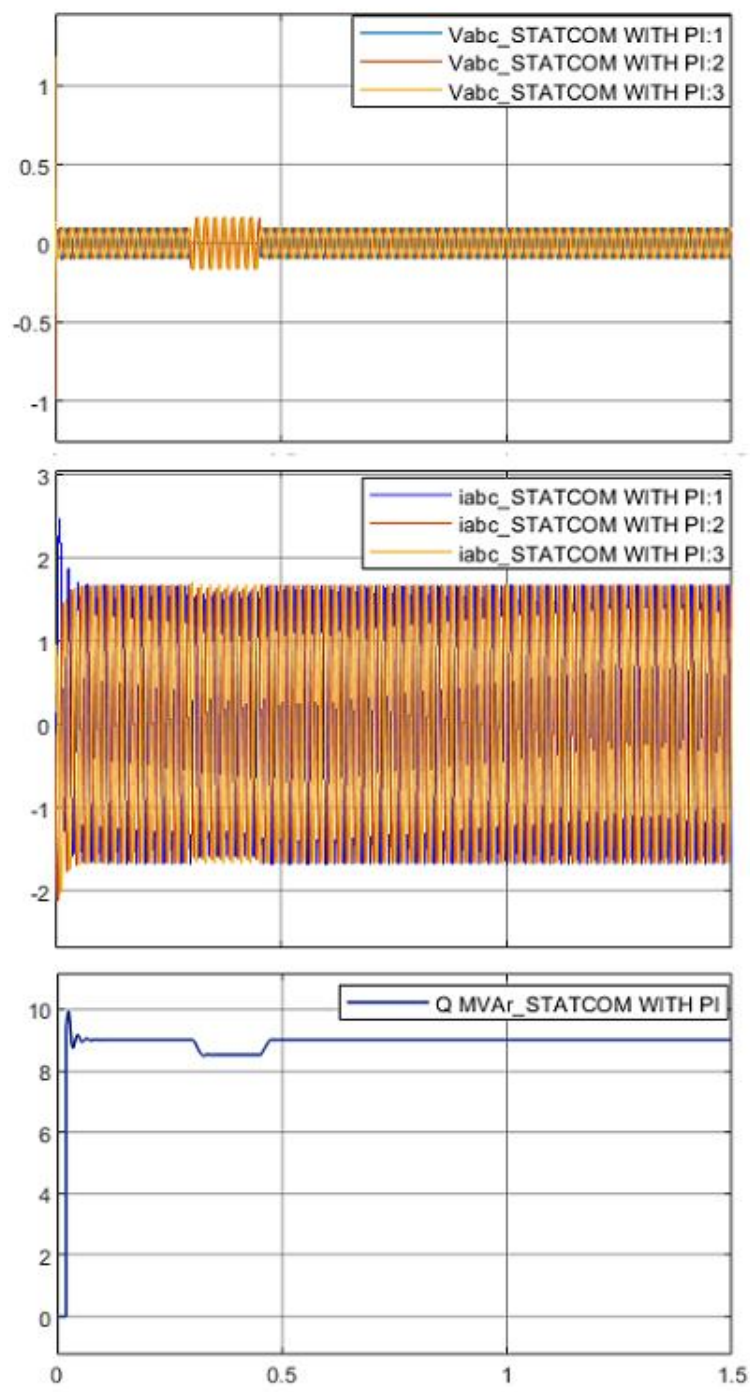

Figure 6: Represents the Voltage, current and reactive Power of STATCOM with PI controller.

In conclusion, the entire reactive power of Fuzzy-PI controller is more stable than conventional controller. As shown in Fig.6 and Fig.7, when the fault at phase A, which locates near at the bus- 2 of the power system, the dropped voltages produced by the three phase transmission lines with coupling transformer are, not so harmful. For which the large reactive power cannot be absorbed, when connected with STATCOM controller. The fluctuations of both real and reactive power produced by Fuzzy-PI controller are very less as compare to conventional controller. But during the ground fault in between Phase A and Phase B, the dropped voltages may be very harmful. Because it absorbs more reactive powers than only in the phase A fault.
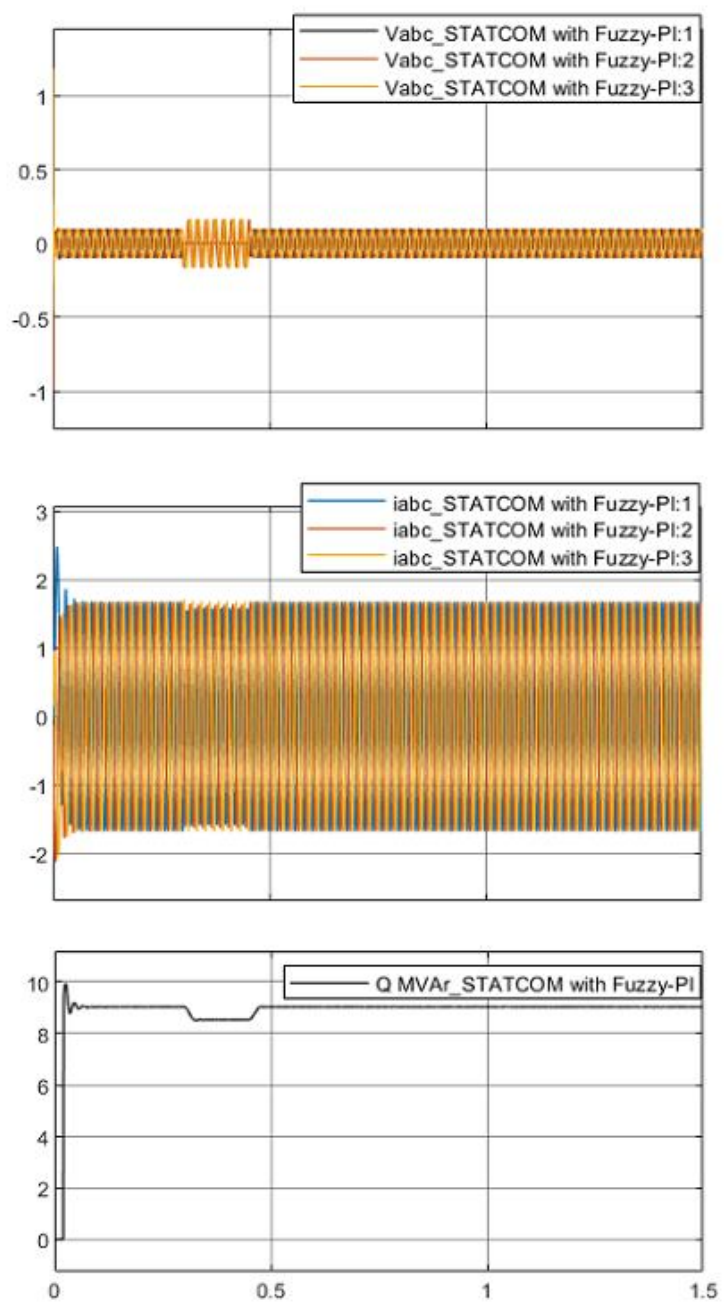

Figure 7: Represents the Voltage, current and reactive Power of STATCOM with Fuzzy-PI controller.

To recompense the necessity as also reduced the amount of reactive power for the grid during fault period ,the STATCOM with Fuzzy-PI protection is the best solution instead of conventional protection. As seen in Fig.7,the STATCOM with Fuzzy-PI controller on the basis of DFIG based wind farm would be set up the degenerate of the current at the rotor side before or after the fault period at the grid. Substantially there will be decrease in the fluctuations of rotor currents as well as harmonics distortions. So that stimulates the breakdown capacity as also enhanced the Low voltage-ride through Capacities of the DFIG based wind generations system.

\section{CONCLUSION}

The type FLC of a Mandeni was used as controller of STATCOM which is connected to the DFIG based wind 
generation system. A comparative analysis was performed between conventional controller and Fuzzy-PI controller of STATCOM. The comparative findings show that Fuzzy-PI controller has better output during transient faults with less overshoot as compare to conventional controller. Based on the output response, the STATCOM with fuzzy-PI controller would causes comparatively smaller fluctuations with more stable in case of the reactive power performance. With a shortened settling time, the Fuzzy PI controller gives greater damping oscillation, rapid and smooth reaction under conditions of fault. Furthermore, STATCOM also have fast terminal voltage recovery following to clearing the fault. However in conclusion, it's clear that the STATCOM contributes best outputs especially if such devices are operated by fuzzy PI control based on fractional order. The integration of Fuzzy PI control robustness and fractional-order accuracy would perfectly increase efficiency of the overall device in comparison with traditional ones.

\section{REFERENCES}

1. Yang, L., Xu, Z., Ostergaard, J., Dong, Z. Y., \& Wong, K. P.(2011). Advanced control strategy of DFIG wind turbines for power system fault ride through. IEEE Transactions on power systems, 27(2), 713-722.

2. Zhang, L., Jin, X., \& Zhan, L. (2012). Rotor voltage analysis of doubly fed induction generator under unsymmetrical grid voltage dips. Dianli Xitong Zidonghua(Automation of Electric Power Systems), 36(14), 136-142.

3. Lei, L., Shengtie, W., \& Guizhen, T. (2016, June). Grid power quality improvement with STATCOM/HESS for wind turbine with squirrel-cage induction generator. In 2016 IEEE 11th Conference on Industrial Electronics and Applications (ICIEA) (pp. 2552-2557). IEEE.

4. Awasthi, A., Gupta, S. K., \& Panda, M. K. (2015). Design of a Fuzzy Logic controller based STATCOM for IEEE9 bus system. European Journal of Advances in Engineering and Technology, 2(4), 62-67.

5. S. Elkhadiri, P. L. Elmenzhi and P. A. Lyhyaoui, "Notice of Violation of IEEE Publication Principles: Fuzzy logic control of DFIG-based wind turbine," 2018 International Conference on Intelligent Systems and Computer Vision (ISCV), Fez, 2018, pp. 1-5, doi: 10.1109/ISACV.2018.8354036.

6. Boroujeni, H. Z., Othman, M. F., Shirdel, A. H., Rahmani, R., Movahedi, P., \& Toosi, E. S. (2015). Improving waveform quality in direct power control of DFIG using fuzzy controller. Neural Computing and Applications, 26(4), 949-955.

7. Raju, S. K., \& Pillai, G. N. (2016). Design and real time implementation of type-2 fuzzy vector control for DFIG based wind generators. Renewable Energy, 88, 40-50.
8. Mohanty, K. B., \& Pati, S. (2016, April). Fuzzy logic controller based STATCOM for voltage profile improvement in a microgrid. In 2016 Annual IEEE Systems Conference (SysCon) (pp.1-6). IEEE. 